\title{
Activity in the Classroom: Interventions to Increase Activity and Help Fight Childhood Obesity
}

\author{
Melissa G Bublitz ${ }^{1}$ and Jordan Rhodes ${ }^{2}$ \\ ${ }^{1}$ University of Wisconsin Oshkosh, WI United States \\ ${ }^{2}$ Center for Entrepreneurship and Innovation, Mission Move ${ }^{\mathrm{TM}}$ Founder, WI United States
}

Corresponding author: Melissa G Bublitz, University of Wisconsin Oshkosh, WI, 800 Algoma Blvd Oshkosh, WI 54901, UNITED STATES, Tel: 920-858-2355; E-mail: bublitzm@uwosh.edu

Received date: December 29, 2016; Accepted date: January 31, 2017; Published date: January 03, 2017

Citation: Bublitz MG, Rhodes J (2017) Activity in the Classroom: Interventions to Increase Activity and Help Fight Childhood Obesity. J Child Obes 2: 3.

Copyright: (c) 2017 Bublitz MG. This is an open-access article distributed u nder t he terms of $\mathrm{t}$ he Creative Co mmons Attribution Lice nse, which permits unrestricted use, distribution, and reproduction in any medium, provided the original author and source are credited.

\section{Abstract}

As schools focus on academics, less time is devoted to physical activity. Students "lack daily, quality physical activity", and this decline in physical exercise is contributing to the prevalence of childhood obesity. In this research we investigate how using a video-based exercise program in the classroom specifically designed to incorporate exercise with math skill practice can increase the activity level of children without sacrificing academic performance. Teachers from 36 Kindergarten and 1st grade classrooms participated in a 12week pilot test using an academic exergaming program (Mission Move ${ }^{\mathrm{TM}}$ ) including both an intervention group and a control group who did not use the software during the test period. Teachers in both the intervention and control groups participated in surveys to assess children's activity levels and classroom behavior over the test period. Further, math pre- and post-tests were administered in both intervention and control classrooms with scores aggregated at the classroom level. We find that the total number of active minutes reported by classrooms during the pilot-test increased more than 100 minutes a week including 20 minutes within the classroom environment on average. Importantly, spending more activity time did not significantly impact academic scores on math skills positively or negatively. This research demonstrates that education-focused activity interventions can increase the activity level of children without having a negative impact on their overall academic performance.

Keywords: Activity; Physical activity; Activity level; Activity breaks; Activity minutes; Childhood obesity; Physical exercise; Classroom behaviour

\section{Introduction}

Despite intensive efforts by health and public policy advocates, the obesity epidemic in the United States continues to grow; two-thirds of adults [1] and approximately one-third of all children in the U.S. [2] are overweight or obese. To complicate the problem, the CDC [3] reports that students "lack daily, quality physical activity" in schools. In fact, research indicates that approximately two-thirds of public schools fail to meet minimum physical education standards with only $17 \%$ of kindergarteners meeting the recommended minimum level of activity [4]. Further these researchers estimate that increasing activity by 60 minutes a week would have a positive influence on obesity rates among children [4]. Increasing physical education and free play in the school environment is at odds with changing policies designed to increase the time devoted to academics and testing. The result has been a decline in the number of minutes children spend each day being active at school which continues to decrease as children progress through our educational system [3]. In this research we investigate a market-based solution and its ability to increase activity levels of children at school while not sacrificing educational outcomes and learning.

\section{Literature Review}

\section{Physical activity of children}

The declines in the activity of children is increasingly perceived as a public health concern, a pressing social problem [5] and a contributing factor in the rise of childhood obesity [6, 7]. Further, multiple agencies including the Centers for Disease Control (CDC) and U.S. Department of Health and Human Services as well as a growing body of research demonstrates that physical activity is critical to both improving academic outcomes for children but also to advancing their health [7, 8]. While video games, TV, and other forms of screen time have been identified as factors in declining activity levels [9] other researchers are investigating exergaming as a way to get children to enjoy physical activity and increase their exercise motivation [10].

In addition to the academic and health outcomes of increasing physical activity of children in the school environment, researchers have also been investigating the relationship between activity levels and classroom behavior. Even small bursts of activity dispersed throughout the day has be shown to increase academic performance and academic 
behavioral outcomes. Specifically, concentration (as well as math fluency) increased when second grade students engaged in five minutes of vigorous activity within the classroom approximately one hour after lunch [11]. Other research from Mahar and colleagues [12] demonstrates that 10 minutes of movement during academic instruction given to third and fourth graders increased on-task behaviors in the classroom. Despite the growing body of research building support for more physical activity inside of and outside of the classroom, our pre-test of teachers' attitudes toward activity levels in their school reveal that $66.7 \%$ of teachers $(\mathrm{N}=36)$ believe their school's efforts to increase student activity levels is only "somewhat effective". In addition, teachers estimate that children are only actively moving in the classroom for an average of 18 minutes per day and only 87 minutes per week with cost and time being reported as the largest barriers to increasing activity in the classroom. Based on this initial survey of teacher's attitudes, we developed an intervention-based experiment to assess if vigorous activity integrated with math skill exercises would increase activity levels and academic outcomes as well as positively influence classroom behavior.

\section{Exergaming}

While video games are often criticized in the popular press as contributing to an increase in screen time and decreasing activity levels of children, the growth of active games has also been investigated as a way to increase activity by embedding activity within video games including popular commercial systems such as the Wii and the Xbox Kinect. Research on the use of exergames to increase the activity level of children is mixed. Studies show that when children are directed to use popular exergames on Wii system (such as Tennis, Boxing, and Dance Dance Revolution) activity levels of children increase [13]. However, more recent work published in Pediatrics shows that in a naturalistic environment where children are given but not prompted to utilize active games there is no evidence that access to exergames increases activity levels [14]. One explanation for the differences may depend on internal motivations to play. Klein and Simmers [10] demonstrate that these types of active games may positively impact on activity levels if players find the games entertaining providing enjoyment and an intrinsic motivation to play.

In this research, we examine activity and other possible benefits of using exergames in the classroom environment. Specifically, we investigate the effects of an exergame built on an educational platform delivered in the classroom environment, combining body weight exercises with math skill practice, on activity, academic performance and classroom behavior. In contrast to Klein and Simmers [10], classroom use of exergames may provide external motivation by empowering teachers to play a critical role in increasing activity levels of children. If teachers believe that the time spent on exergames can not only increase activity levels but also advance the academic and behavior goals they have for their classrooms, devoting time to activity within the school day may increase. Further, classroom use of the software as an activity break for all students in the classroom removes a child's opportunity to "optout" of exercise so that we are able to control for individual differences in children's intrinsic motivation to exercise. We hypothesized that classrooms that implemented these short video-based activity breaks that also encourage math skill practice aligned with the common core standards by grade level, would not only increase their activity levels but also show improved classroom behavior.

\section{Methodology}

\section{Sample \& software description}

During a live pilot test of an exergame product based on an educational platform, 36 Kindergarten (ages 5-6) and 1st grade classrooms (ages 6-7) from schools across two neighboring suburban school districts in northeast Wisconsin, U.S.A. participated in a 12-week test, using the academic exergaming program in the classroom. Table 1 presents a brief demographic profile of the two districts based on 2015 U.S. Census data [15].

Table 1: 2015 Demographic Profile Census Data.

\begin{tabular}{|c|c|c|}
\hline & $\begin{array}{l}\text { Test Group } \\
\text { City }\end{array}$ & $\begin{array}{l}\text { Control Group } \\
\text { City }\end{array}$ \\
\hline Total Population & 42,696 & 66,083 \\
\hline \multicolumn{3}{|l|}{ Gender } \\
\hline Female & $51.00 \%$ & $48.10 \%$ \\
\hline \multicolumn{3}{|l|}{ Race/Ethnicity ${ }^{*}$} \\
\hline White & $90.30 \%$ & $89.00 \%$ \\
\hline African American & $1.60 \%$ & $4.10 \%$ \\
\hline Hispanic/Latino & $4.20 \%$ & $3.00 \%$ \\
\hline American Indian & $1.20 \%$ & $0.40 \%$ \\
\hline Asian & $2.80 \%$ & $2.70 \%$ \\
\hline
\end{tabular}




\section{OTHER}

$1.60 \%$

$0.20 \%$

*In the test group city, $1.5 \%$ identify as more than one race, in the control group city, $1.4 \%$ identify as more than one race

While the number of students who participated was high ( $N=665$ students) all data was aggregated at the classroom level resulting in a final sample of 36 classrooms. With permission of the two school districts, teachers were recruited to participate.

The only incentive offered was a \$25 gift card for teachers who administered the pre/post-test of math skills in their classroom and completed surveys to assess activity levels and classroom behavior. No other incentives were offered to either group. Of the 36 classrooms, eight classrooms selected as a control group and did not use the product but did participate in the data collection across the same time period.

One district comprised the control group. This was done because teacher training and curriculum decisions within this geographic region typically occur at the district level. Keeping the control group to one district helped limit the possibility that any differences in academic scores or behavior in the classroom observed could be attributed to differences in what was taught during the test period or any behavior management systems in place at the district level.

The product selected for testing was a new product currently in research and development titled Mission Move ${ }^{\mathrm{TM}}$ which delivers appropriate math skill practice by grade level set to body weight exercises such as jumping jacks.

The math skill activities were created by a certified curriculum developer familiar with the grade level standards in the state. The exercises were evaluated to ensure they were appropriate considering the fine and gross motor skills of the age group, children ages 5-7.

This is an online product currently in development where teachers have flexibility to decide usage length intervals as well as which specific math skill to practice by choosing from a list that correlates to the curriculum standards within the state where the product was being tested.

As an example, teachers could select to practice the concept of "greater than, less than" for four minutes if they finished a lesson early and wanted to give students an activity break before going on to the next classroom task planned.

Teachers accessed the test product online and played the guided math practice activity paired with a specific body weight exercise on their classroom SMART board or classroom projector.

Continuing with the previous activity example, students might be asked to jump to the side that displays more apples, then jump to the side with fewer bananas, etc. Figures $1 \mathrm{a}$ and $1 \mathrm{~b}$ show screen shots of the software as it displays to the class.

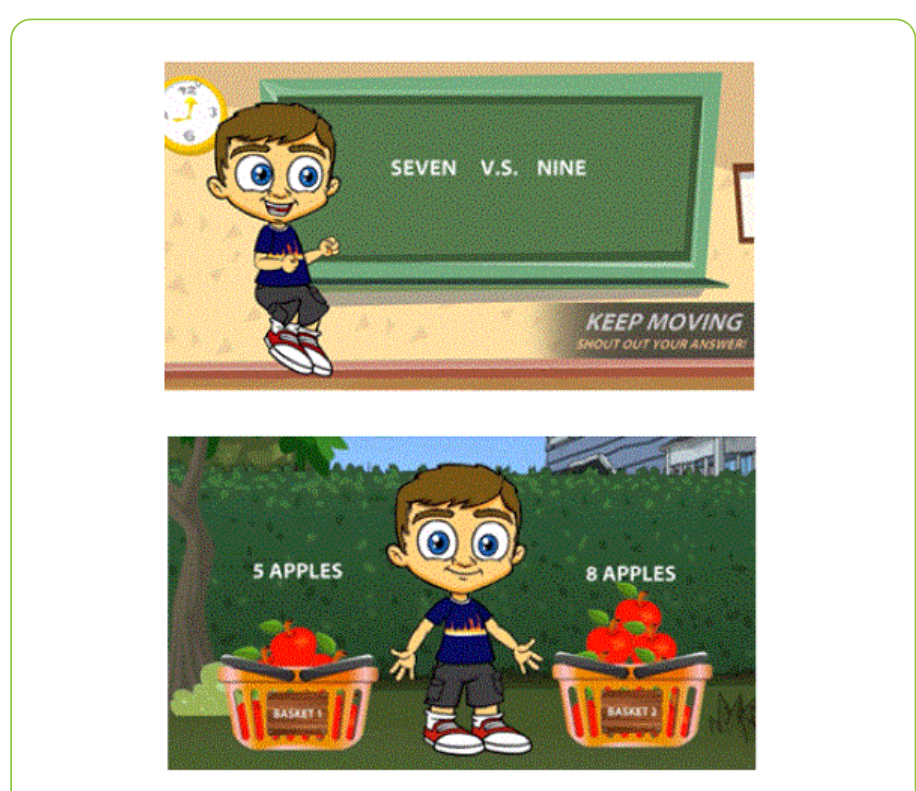

Figure 1a and 1b: Sample Screen Shots from Mission Move ${ }^{T M}$.

\section{Data collection}

This study assesses the impact of small bursts of physical activity embedded within the classroom on activity levels, academic (math) skills and classroom behavior. The study compares academic and classroom performance data using preand post-test data from those in the intervention group to those in the control classrooms. A certified curriculum designer familiar with grade level math skills required developed a math assessment tool which was administered to students on two instances: immediately prior to pilot test period and again at the end of the 12-week intervention. The same grade appropriate math test was used in both the intervention and control group [16-18]. The tests were graded by an independent grader based on the answer key provided by the curriculum designer. The grader was blinded to the experimental condition and did not have any data about which students or classrooms were part of the control or intervention group. Student scores on the math test based on the number of correct answers given out of 40 possible points, were averaged by classroom.

Every three weeks during the pilot test period, teachers participated in an online survey to assess activity levels and classroom behavior. As part of the survey teachers rated the overall behavior of their classroom using a set of scales adapted from Alexander et al., [19]. In addition, teachers were asked to estimate for their classroom on the survey week (a) the number of negative behavior incidents, (b) the percent of the day (on average) students were off-task in the classroom, (c) the number of activity minutes outside of class students logged, and (d) the number of activity minutes inside of class students logged. 
Over the same test period we collected the same set of classroom measures - pre/post math test of students plus teacher surveys about activity and behavior - from a sample of teachers/classrooms who were not participating in the intervention to serve as a control group. This longitudinal, repeated measures design allows us to not only compare our intervention of integrating math skill practice with physical activity to a control group but also allows us to examine the possibility of effects on behavior in the classroom over time. All measures and analysis are aggregated at the classroom level resulting in our final sample use to compare the performance of intervention classrooms $(\mathrm{N}=28)$ to control classroom $(\mathrm{N}=8)$.

As previously stated, we hypothesized that classrooms that implemented these math based activity breaks, would not only increase their activity levels but also show improved classroom behavior. Research shows that online games that actively engage students to respond by asking a question to which children can respond directly may increase learning $[17,18]$.

Accordingly, we hypothesized that at a minimum academic performance would not be negatively impacted by devoting more time to increasing children's activity level at school and perhaps may even provide some academic benefits over time compared to the control group. We used SPSS to compare averages on math test scores of the two groups, we also compared the group averages of teachers' estimates of activity levels and their perceptions of behavior in the classroom using SPSS.

While we collected survey data every 3 week, the math performance was only assess at the start and end of the 12week pilot test. Here, we present our findings of both teacher survey data and academic performance by comparing the start and end of the test period. We expected to find that integrating small bursts of activity increases overall activity and has a positive effect on classroom behavior among children in this age group (ages 5-7 years old).

\section{Results}

First and foremost, based on teachers' estimated activity minutes provided each survey week, the pilot program increased activity levels of the intervention group compared to our control group during the pilot test period. A repeated measures ANOVA test revealed a significant interaction between the pre/post total minutes estimated by teachers and the test condition as compared to those in estimated by the control group ( $F=6.131$, $p=0.022$ ).

Post-hoc contrast tests (Wilk's Lambda) revealed a significant increase in the average total activity minutes (inside and outside of the classroom) within the intervention group whose activity increased from 180 minutes during the pretest (Mpre $=180$, $\mathrm{SD}=123.22, \mathrm{~N}=28$ ) to 310 minutes in the post-test. (Mpost=310, $\mathrm{SD}=156.84, \mathrm{~N}=28$ ).

By comparison, within the control group, the change in total activity minutes reported was not significant, comparing 193 minutes (Mpre=193, $S D=150.00, N=8$ ) to 218 minutes
(Mpost=218, SD=118.49, N=8). Figure 2a shows that "Total Minutes: Inside \& Outside Classroom" is estimated to have increased by almost $75 \%$ compared to only $10 \%$ in the control group.

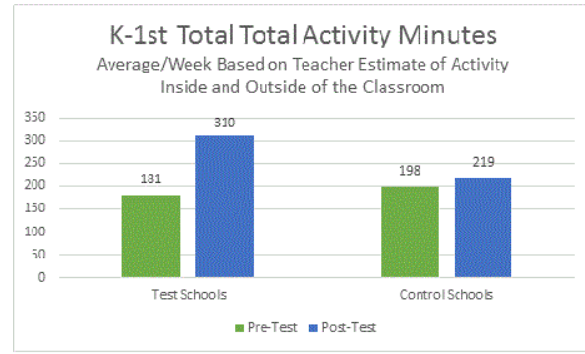

Figure 2a: Total Minutes Active: Inside \& Outside Classroom.

Further, teachers estimate that minutes active inside the classroom increased by $50 \%$ in the intervention group compared to a slight decrease in the control group as the calendar progressed, as shown in Figure $2 \mathrm{~b}$, however, due the small sample size this interaction was not statistically significant.

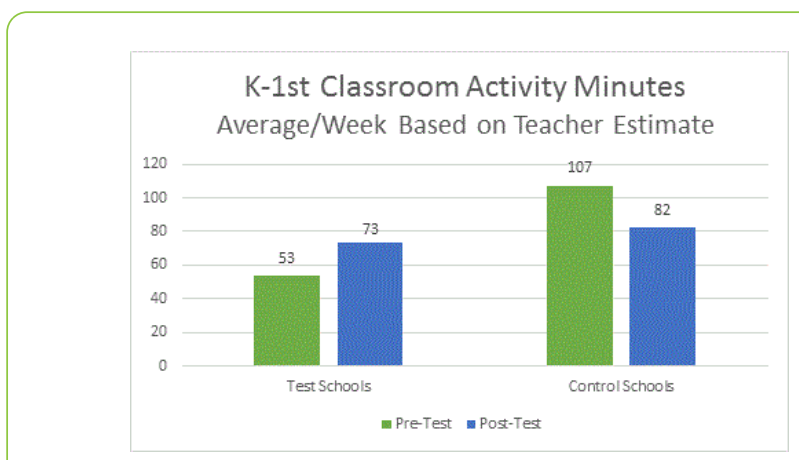

Figure 2b: Minutes Active Inside The Classroom.

We recognize that using the teacher's estimates of activity levels may not be as accurate as actual activity levels and this issue is discussed more fully in the Research Limitations sections. However, we have two measures that we used to assess the reliability of the data reported for the intervention group. Specifically, we were able to measure the actual minutes of use for each classroom participating in the intervention group. System usage data shows that classrooms in the intervention group used the Mission $\mathrm{Move}^{\mathrm{TM}}$ software an average of 29 minutes while teachers in this group reported an average increase of 20 minutes. Further, we ran a correlation between the actual minutes of use and the growth of activity reported in the classroom based on the pre and post-test surveys and found a moderately high correlation between the minutes classrooms logged in the system and the growth of their estimated minutes of activity for their specific classroom (Pearson Correlation Coefficien $=0.769, p=0.077$ ). However, because we have no system usage data for those in the control group we cannot compare the two groups on actual activity, only on teacher estimates of activity. While we recognize that the teachers' estimates of activity levels do not perfectly 
correlate to actual activity minutes, these results give use confidence that their estimates are reasonably good.

As indicated in our introduction and literature review, one reason given for decreasing organized physical activity in schools is the increasing academic and testing demands on schools. However, as the literature shows, physical activity may actually serve to enhance academic performance due to increased attention and better behavior in the classroom [7]. Comparing the aggregate pre/post-test scores of those classrooms in our pilot study to those in our control group, we found directional support for academic improvement in the intervention schools though the small sample size does not show a significant statistical difference in academic performance between the two groups. However, since one key fear of administrators and teachers is that taking classroom away from their students may undermine academic performance, at a minimum this research indicates that increasing activity in this way - small bursts within the classroom throughout the day - does not appear to negatively affect academic performance. Figure 3 compares the aggregate pre/post-test scores (maximum of 40 correct points) on the math skills test comparing the pilot test schools to the control group. As you would expect to find throughout the school year, both groups show a gain in academic performance over the 12-week period.

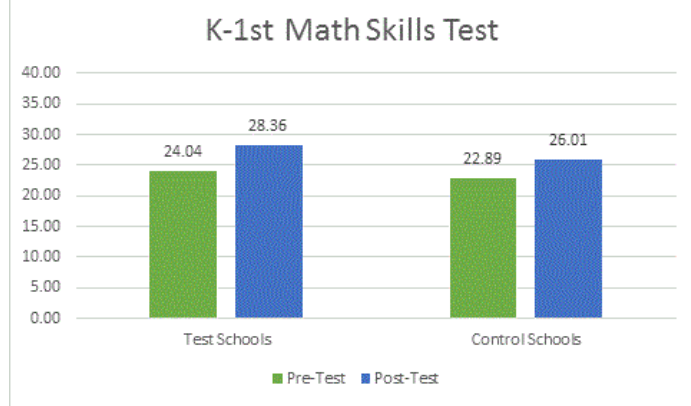

Figure 3: Academic Performance.

However, this research also shows that spending time using the software to increase activity levels inside the classroom does not negatively impact academic performance. A repeated measures ANOVA used to test the interaction between academic performance on the math skills pre/post-test comparing the intervention to control group was not significant $(F=1.048$, $\mathrm{p}=0.316)$. More research including longer test period and a larger sample would provide a more robust test of the impact of small bursts of activity in the classroom academic performance.

Finally, we found directional support for the idea that increasing activity in the classroom may decrease negative behavior in the classroom. Figure 4 shows that teacher reports of negative behavior incidents per week decreased in the intervention classrooms more than it did in the control schools. Such reports included reports of tantrums, fights, teasing, and other negative behaviors that disrupt the classroom. Once again this data was collected through the periodic weekly surveys of teachers comparing the number of incidents reported at the start of the 12-week pilot test to those reported at the end of the test period. While the difference between the groups assessed with a repeated measures ANOVA test was not statically significant $(F=1.89, p=0.185)$, we believe these preliminary results begin to show that integrating small bursts of activity throughout the day may not only increase activity levels but help with academic performance by reducing negative behavior incidents in the classroom

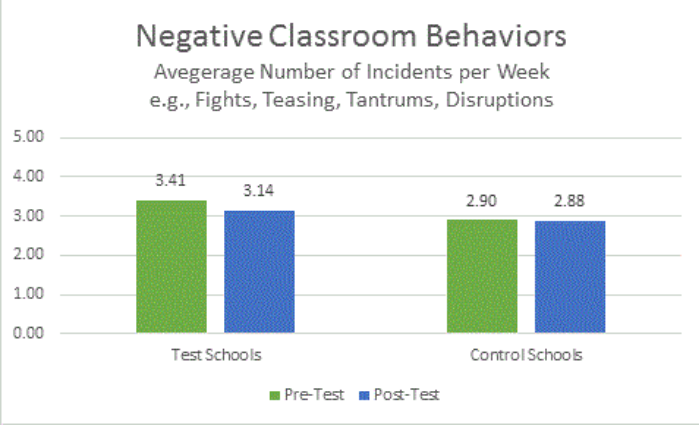

Figure 4: Classroom Behavior.

\section{Limitations \& Future Research}

This research was designed to add to the growing body of literature that indicates that increasing the activity levels of children in schools does not undermine academic performance and may in fact help classrooms function with fewer disruptions. Our research tests on integrating small bursts of activity while practicing math skills only lasted 12 -weeks and was only conducted in a small number of classrooms in a limited geographic region of the United States. We believe this research provides some initial evidence of the potential gains of using education focused activity breaks but needs to be follow-up with a much larger test on a wider audience. More research is needed to determine if the activity gains experienced can be sustained with continued use over the school year or if usage and activity gains will lag after the novelty wears off. In addition, conducting a larger test over an extended time period may provide more answers to the questions about the impact of increased activity on classroom behavior and academic performance. Another key limitation of our rather small sample of schools was that it was conducted in a region of the U.S. that is not particularly diverse. More research should be conducted in schools with more diversity including racial and ethnic makeup as well as a wider range of age groups, socio-economic levels, and climate factors.

In addition, future researchers should explore individual differences in school and teacher motivations to use this approach within their classroom environment as teacher/ administrator attitudes toward incorporating this form of activity in their classroom may impact utilization levels. This is particularly important because much of the data used in this research was based on the teacher surveys and their assessment of their classroom. Future research should continue to identify more direct measures of activity levels and classroom behavior to validate these initial findings. Student motivations to participate in activity should also be investigated as one 
potential benefit we did not explore is the power of creating positive activity habits and attitudes in children over time. Considering these limitations, the evidence presented here only starts to answer questions about how we can get kids more active without interfering in the growing curriculum demands teachers face in their classrooms.

\section{Conclusions}

Using a video based exercise program in the classroom may provide a new way to increase activity levels of children without undermining academic performance. Integrating small bursts of activity while practicing math skills not only reinforces academic skills but can also increase the activity level of children. Children specifically stand to benefit as system utilization over our test period showed an average increase of 29 active minutes per week. While small, this difference could be very meaningful in the life and health of children as research demonstrates that increasing activity even in small amounts can meaningfully impact the obesity rates of children [4]. More broadly, the active "brain breaks" these programs offer may also teach children that you can work activity into your day, through small bursts, and help lead to more active lifestyles as well as academic performance outcomes in children $[19,20]$. Making exercise entertaining and fun may open the door to seeing opportunities to be active in other parts of their day [5]. Other research on exergames has shown that beyond the benefits associated with added activity minutes, these kinds of games may increase a player's fitness motivation [10]. While we did not investigate individual children's exercise self-efficacy, with increased practice we expect children's fine and gross motor skills as well as their fitness levels may also improve. Future research should also examine how children's attitudes toward activity and their fitness motivation may be influenced by integrating more activity into the classroom and into the child's day.

Making progress on the solving the multifaceted problem of childhood obesity will require actions by individuals, parental, physicians, schools, marketing entities, and public policy advocates to create a community environment supportive of healthy choices and behaviors [6, 21, 22]. This research provides some preliminary evidence that short exercise activity breaks throughout the day combined with academic skills practice have the potential to enhance academic outcomes and improve classroom behavior by getting kids more active. Future research is needed to assess the benefits in a larger sample of classrooms and the potential for these results to be sustained or enhanced over a longer time period. It is our hope that if this type of software intervention yields positive results that schools, administrators and policy makers will make activity in the classroom a higher priority. Further, armed with high quality research data, schools and state governments may be more motivated to use resources to help teachers implement a curriculum-based exercise program within the classroom and not reserve activity for physical education outside of the classroom. Getting students active may not only help advance educational outcomes but also supplement other efforts to fight the obesity epidemic and encourage children to live active, healthy lives.

\section{References}

1. Ogden CL, Carroll MD (2010) Prevalence of overweight, obesity, and extreme obesity among adults: United States, trends 19601962 through 2007-2008. CDC National Center for Health Statistics.

2. Ogden CL, Carroll MD, Kit BK, Flegal KM (2012) Prevalence of obesity and trends in body mass index among US Children and Adolescents, 1999-2010. Journal of the American Medical Association 307: E1-E8.

3. http://www.cdc.gov/healthyyouth/physicalactivity/facts.htm

4. Cawley J, Frisvold D, Meyerhoefe C (2013) The impact of physical education on obesity among elementary school children. Journal of Health Economics 32: 743-755.

5. Garnier P (2013) Objects for a "healthy lifestyle": Children's material culture and physical activities. Young Consumers 14 331-341.

6. Ayadi K, Young B (2006) Community partnerships: preventing childhood obesity. Young Consumers 7: 35-40.

7. Strong WB, Malina RM, Blimkie CJR, Daniels SR, Dishman RK, et al (2005) Evidence based physical activity for school-age youth. The Journal of Pediatrics 146: 732-737.

8. CDC (2010) The association between school-based physical activity, including physical education and academic performance. Atlanta, GA: US Department of Health and Human Services.

9. Larwin KH, Larwin DA (2008) Decreasing excessive media usage while increasing physical activity'. Behavior Modification 32: 938-56.

10. Klein MJ, Simmers CS (2009) Exergaming: virtual inspiration, real perspiration. Young Consumers 10: 35-45.

11. Maeda JK, Randall LM (2003) Can academic success come from five minutes of physical activity? Brock Education, 13: 4-22.

12. Mahar MT, Murphy SK, Rowe DA, Golden J, Shields AT, et al. (2006) Effects of a classroom-based program on physical activity and ontask behavior. Medicine and Science in Sports and Exercise 38: 2086-2094.

13. Wittman G (2010) Video Gaming Increases Physical Activity Journal of Extension 48: Article Number 2TOT6.

14. Baranowski T, Abdelsamad D, Baranowski J, Margareta T, O'Connor Thompson D, et al. (2012) Impact of an active video game on healthy children's physical activity. Pediatrics 129: e636-e642.

15. U.S. Census (2015) American FactFinder.

16. Alexander KL, Entwisle DR, Dauber SL (1993) First-Grade Classroom Behavior: Its Short- and Long-Term Consequences for School Performance. Child Development 64: 801-814.

17. Harding J, Szakacs J, Parry B (2009) Children playing and learning in an online environment: $A$ review of previous research and an examination of six current web sites. Young Consumers 10: 17-34.

18. Hilton R (2006) Gaming as an education tool. Young Consumers 7: 14.

19. Katz DL, Cushman D, Reynolds J, Njike V, Treu JA, et al. (2010) Putting Physical Activity Where It Fits in the School Day: Preliminary Results of the $A B C$ (Activity Bursts in the Classroom) for Fitness Program. Preventing Chronic Disease 7: A82. 
20. Donnelly JE, Lambuorne K (2011) Classroom-based physical activity, cognition and academic achievement. Preventive Medicine 52: S36-S42.

21. Ayadi Kafia (2008) The role of school in reducing the prevalence of child obesity. Young Consumers 9: 170-178.
22. Gard M, Wright J (2005) The obesity epidemic: Science, morality and ideology, Routledge, London. ISBN: 9780415318969. 